Cooper, D.M.; Evans, C.D.; Norris, D.; Thacker, S.; Pereira, M. Gloria. 2014. Application of a simple multiplicative spatio-temporal stream water quality model to the river Conwy, North Wales. Environmental Science: Processes \& Impacts, 16 (7). 1600-1607. 10.1039/C3EM00627A

Copyright $($ The Royal Society of Chemistry 2014

This version available http://nora.nerc.ac.uk/505340/

NERC has developed NORA to enable users to access research outputs wholly or partially funded by NERC. Copyright and other rights for material on this site are retained by the rights owners. Users should read the terms and conditions of use of this material at http://nora.nerc.ac.uk/policies.html\#access

This document is the author's final manuscript version of the journal article following the peer review process. Some differences between this and the publisher's version may remain. You are advised to consult the publisher's version if you wish to cite from this article.

http://www.rsc.org

Contact CEH NORA team at noraceh@ceh.ac.uk

The NERC and CEH trademarks and logos ('the Trademarks') are registered trademarks of NERC in the UK and other countries, and may not be used without the prior written consent of the Trademark owner. 


\section{Application of a simple multiplicative spatio- 2 temporal stream water quality model to the river 3 Conwy, North Wales}

4

5 DM Coopert ${ }^{*}$, CD Evanst, D Norrist, S Thackerł and M. Glória Pereirał

6 TCEH Bangor, Environment Centre Wales, Deiniol Road, Bangor, LL57 2UW, UK

$7 \quad$ $\quad$ CEH Lancaster, Library Ave., Lancaster, LA1 4AP, UK

$9 *$ Corresponding author

10 Tel: +44 (0) 1248 374500. Fax: +44 (0) 1248 362133. Email: cooper@ceh.ac.uk

11 CEH Bangor, Environment Centre Wales, Deiniol Road, Bangor, LL57 2UW, UK

\section{Abstract}

13 We use a simple multiplicative spatio-temporal model to describe variability in a

14 sequence of water quality monitoring data from headwater streams in the Conwy

15 catchment, North Wales. The spatial component of the model treats concentrations as

16 due to simple mixing of a small number of distinct source types, each associated with

17 particular upstream catchment characteristics. The temporal component allows

18 concentration variability due to seasonal or hydrological change. We apply the model

19 using three candidate catchment characteristic classifications to generate mixing 1

C:\Users\dgal\Desktop\N505340.docx 
1 concentrations, and a seasonal component to describe temporal variability, and test a

2 range of sub-models. We identify a cross-classification of soil and land cover as

3 providing the best spatial indicator of water quality of the classifications considered.

4 The spatial model based on a selected grouped cross-classification was shown to

5 account for between $35 \%$ and $90 \%$ of the spatial variability and the seasonal model

6 accounted for between $45 \%$ and $100 \%$ of the temporal variability in the data.

7 Analysis of residuals showed an inverse relationship between DOC and sulphate and

8 between hydrogen ion concentration and calcium and magnesium. We also found

9 residual correlations between sites which are strongly related to landscape class. These

10 are attributed to landscape class by time interactions which are not accounted for in the

11 simple multiplicative model.

12 Key words: stream water quality; landscape; classification; multiplicative;

\section{Introduction}

14 Stream water quality is measured to determine whether acceptable ecological

15 standards are being met, and to support investigations into the source and fate of

16 material in solution and suspension. Water quality management through contaminant

17 source control is based on the interpretation of the data generated by monitoring

18 programmes. Data collected commonly include repeated measurement of water quality

19 variables at fixed sampling locations, generating spatio-temporal datasets. These give 2

C:\Users\dgal\Desktop\N505340.docx 
1 useful but limited information on the contaminant budget of a catchment, and a fuller

2 spatio-temporal description of water quality variability can be provided by models

3 representing sources and their fates at a range of scales, supported by water quality

4 measurements and other features of the catchment.

5 Stream water quality models may rely on the known distribution of sources and source

6 characteristics to track material in solution or suspension through a stream network.

7 The application of these models does not require stream water quality measurements,

8 though they may be useful for calibration. Alternatively, models may use river water

9 quality measurements to infer source magnitudes given the upstream distribution of

10 source locations, and extrapolate locally based on known source locations upstream of

11 unmonitored stream sites. This approach tailors loss estimation to local conditions, but

12 if used without other knowledge may neglect useful information. For local use, a hybrid

13 approach is to start with a model which includes initial numerical estimates of

14 magnitudes of known source types, and calibrate the model from stream water quality

15 measurements.

16 There are a number of models which use accumulated knowledge of source magnitudes

17 to estimate water quality at new sites. These have been developed largely to account

18 for agricultural diffuse source pollution by the nutrients nitrogen and phosphorus.

19 Losses of these nutrients have been modelled by nutrient budgeting based on farm 3

\section{C:|Users\dgal|Desktop\N505340.docx}


1 management including details of livestock, crop management and drainage

2 characteristics. Losses are estimated by a simple accounting procedure, and are often

3 expressed on an annual basis. Johnes $^{1}$ presents a simple annual loss accounting model,

4 and this approach has been widely adopted ${ }^{2,3}$. Other models estimate losses at a finer

5 timescale and include a component allowing losses to vary according to hydrological

6 conditions. Catchment scale models of this type generally include a delivery component

7 describing transfers to the larger river network, and a routing component describing

8 transfer through the river network, possibly allowing for point sources. These models

9 include $\mathrm{AGNPS}^{4}, \mathrm{SWAT}^{5}, \mathrm{HSPF}^{6}, \mathrm{MAGPIE}^{7}$, and are reviewed by Borah and Bera ${ }^{8,9}$.

10 Models which use stream water quality to infer source magnitudes are generally of

11 regression structure, and may be partially constrained to give some natural mixing

12 interpretation. The simplest such model uses unstructured regression of concentrations

13 on a range of catchment characteristics ${ }^{10,11}$. Unconstrained models of this form may

14 include negative coefficients which have no natural interpretation and which may

15 generate negative concentrations. If logged concentration data are used as response

16 variables, then additive terms imply a multiplicative model of the raw data, which is not

17 compatible with additive contributions from a number of sources. These considerations

18 suggest that the spatial component of a model should be interpretable as a sum of

19 (positive) contributing sources. These simple nutrient accounting models commonly rely

4

C:\Users\dgal\Desktop\N505340.docx 
1 on a landscape classification, with characteristic nutrient or other loss from each class ${ }^{12-}$

2 17. Apart from individual studies, a modelling framework, SPARROW, has been

3 developed for estimation of contributing pollutant sources from stream water quality

4 monitoring data using a constrained regression approach ${ }^{18,19}$. Where there is temporal

5 variability in water quality this may be seasonal or driven by hydrological variability

6 which may be due to a dilution effect of relatively uncontaminated precipitation. A

7 simple dilution effect is multiplicative, affecting all concentrations derived from fixed

8 sources equally. In practice, a hydrological response may mobilise new sources, and

9 precipitation does contain some contaminants. Nevertheless, the dilution argument

10 does suggest a multiplicative term may be appropriate for the temporal component of a

11 simple water quality model. If precipitation is uniform over a wide area, then dilution

12 may be regionally similar. An extension of the SPARROW modelling framework to

13 include a multiplicative temporal effect has been described by Wellen et al. ${ }^{20}$.

15 We apply a simplified version of Wellan et al's ${ }^{20}$ spatio-temporal model in which the

16 spatial component is additive and the temporal component a seasonal multiplier of the

17 spatial component. We examine the performance of the model in describing the

18 variability in concentration changes measured in headwater subcatchments of the

19 Conwy catchment, North Wales. Our model excludes point sources, which are largely

5

C:\Users\dgal\Desktop\N505340.docx 
1 absent from the headwater subcatchments sampled. The influence of any instream

2 processes is assumed to be accounted for through their influence on the estimated

3 drainage concentrations from the landscape classes used at the scale of the headwater

4 subcatchments. The model can be interpreted as assuming simple mixing of end-

5 members generated by a small number of landscape classes, with equal dilution or

6 proportionate generation at equal times, for all end-member sources.

7 We consider three different landscape classification schemes as potential end-member

8 sources for the spatial component of the model. Each scheme is derived from national

9 UK databases. On any sampling occasion, each landscape class is assumed to generate

10 an end-member runoff component with characteristic water quality. Downstream water

11 quality is taken to be a mixture of end members, according to the upstream proportion

12 of each class under the selected classification scheme. The model does not allow

13 interaction between time and space, so that concentrations may not stay fixed for one

14 landscape class while varying in another class. Interaction between landscape classes

15 and temporal effects may be tested through residual analysis. The model is applied

16 individually to a range of variables, so that proportional changes in concentration over

17 time may vary between water quality variables.

18

6

C:\Users\dgal\Desktop\N505340.docx 
1 In our application of the model to the Conwy catchment, water quality is measured

2 quarterly through two years, and given this limited number of sampling occasions, we

3 estimate a seasonal effect only, recognising that this will be influenced by hydrological

4 and other conditions at the time of sampling.

\section{Methods}

6 The spatio-temporal model expresses concentration of a single water quality variable as

7 the product:

8

$$
y_{s, t} \lambda=c_{s} \quad t
$$

9 In equation (1), $y_{s, t}$ is a concentration measurement at location $s=1, \ldots, n_{s}$ and field

10 excursion $t=1, \ldots, n_{t}$. The parameters $c_{s}$ and $\lambda_{t}$ represent the spatial and temporal

11 components of the model. The time parameter $\lambda_{t}$ adjusts simulated concentrations $C_{s}$

12 as they are influenced by such factors as hydrological conditions and season at the time

13 of sampling.

14

15 We extend the model of equation (1) to allow $c_{s}$ to be a function of the configuration of

16 landscape classes within the catchment, which are assumed to be available as a

17 complete fine-scale spatial coverage. In particular, where a catchment property is

7

C:\Users\dgal\Desktop\N505340.docx 
1 distributed upstream of a sampling point, we assume simple mixing of upstream

2 contributions by landscape class, so that

$$
c_{s} \otimes \sum_{j} p_{s, j}
$$

4 where in equation (2) $p_{s, j}$ is the proportion of the headwater subcatchment covered by

5 landscape class $j=1, \ldots, m$ and $\vartheta_{j}$ is the concentration in water draining landscape

6 class $j$ at the defined reference sampling time. This is the functional form of the spatial

7 representation used by Cooper et $a{ }^{13}$ and in terms of fluxes assumes simple mixing of

8 contributions from each class, under the condition that the flow from each class is area-

9 proportional.

10 We further extend the model to allow $\lambda_{t}$ in equation (1) to be a function of time-varying

11 covariates, so

12

$$
\lambda_{t}=f_{t}(\varphi)
$$

13 In equation (3), $f \varphi$ ) is some function whose value at any point in time depends on the

14 parameter array $\varphi$. Combining equations (1), (2) and (3) gives

$$
y_{s, t} \vartheta=\left(\sum_{j} \mathscr{R}_{s, j} j\right)\left({ }_{t}()\right)
$$

$$
\log \left(y_{s, l} \vartheta\right)=\log \left(\sum_{j} f p_{s} \varphi_{j}\right)+\log \left({ }_{t}()\right)
$$

8

C:\Users\dgal\Desktop\N505340.docx 
1 Our hypothesis is that equation (4) explains sufficient of the variability in concentrations

2 to be useful for estimating of water quality in headwater streams at large temporal and

3 spatial scales. We include random terms in the logarithmic form of equation (4), giving

4

$$
\begin{aligned}
\log \left(y_{s, t} \lambda\right) & =q_{s}+{ }_{t}+{ }_{s, t} \\
c_{s} & \otimes \log \left(\varsigma \sum_{j} p_{s, j}{ }_{j}\right)+{ }_{s} \\
\lambda_{t} & \left.=\log \left(\begin{array}{ll}
f_{t} \phi & k
\end{array}\right)\right) \xi_{t}
\end{aligned}
$$

5 In equation (5) $\varsigma_{s}$ is a random site effect, $\xi_{t}$ a random sampling occasion effect, and

$6 \quad \eta_{s, t}$ a residual error term assumed uncorrelated in time and space. Wellen et al. ${ }^{20}$ also

7 include temporal correlation in their model through a random walk structure for the

8 temporal parameters. Because we apply the model only to independent headwater

9 subcatchments for we ignore instream losses (Wellen et al's ${ }^{20} H_{i, j}^{s}$ and $H_{i, j}^{R}$ ). While

10 equation (5) is the most complete form of the model used, we also consider sub-models

11 which excluding the fixed effects $\vartheta_{j}$ and $\varphi_{k}$.

12 The models are applied to a number of measured water quality variables, and

13 inferences made on the relationship between these variables through studying both

14 estimated model parameters and residual series.

\section{Application}

9

C:\Users\dgal\Desktop\N505340.docx 


\section{$1 \quad 3.1$ Spatio-temporal survey}

2 We sampled stream water from 39 independent headwater subcatchments of the

3 Conwy catchment in North Wales (Fig 1).

C:\Users\dgal\Desktop\N505340.docx 


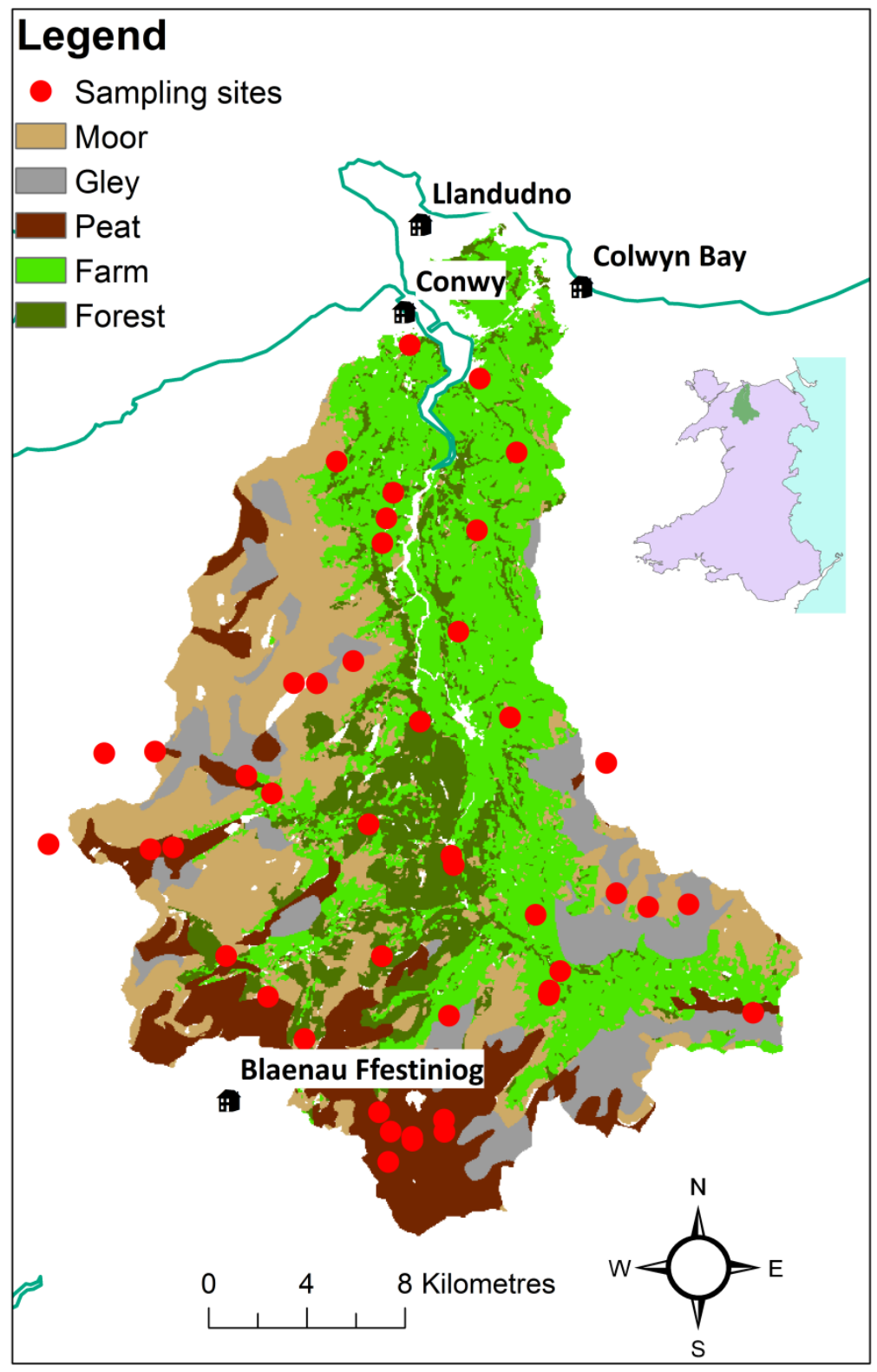

1

Figure 1. The Conwy catchment, North Wales 
1 The Conwy catchment $\left(3^{\circ} 50 \mathrm{~W} 53^{\circ} \mathrm{N}\right)$ includes a range of common upland UK landscapes

2 ( $73 \%$ of the catchment is above $200 \mathrm{~m}$ compared with $28 \%$ of the UK) with the main

3 components being the mountains and moorland of Snowdonia, plantation forestry with

4 non-native coniferous species, and enclosed improved grazing land for sheep and cattle.

5 There are smaller areas of broadleaved woodland and little urbanisation. Elevation

6 varies from sea level to $1060 \mathrm{~m}$, with rainfall between 600 and $3000 \mathrm{~mm} \mathrm{yr}^{-1}$. The

7 catchment above the tidal limit is described in detail by Evans et al. ${ }^{14}$.

8 The subcatchments monitored are upstream of registered point sources such as sewage

9 treatment works or industrial effluent discharge, most draining uninhabited moorland

10 or forest. A small number of farmed subcatchments included farm buildings where

11 washings from yards or seepage from septic tanks. Such indeterminate sources are

12 taken as contributing to the overall diffuse source contribution for the purposes of this

13 analysis. Samples were collected at each subcatchment site on eight occasions at three-

14 monthly intervals between September 2008 and June 2010.

15 Headwater subcatchments were chosen with the aim of providing good estimates of

16 model parameters rather than to estimate population values of variables. To this end

17 they were selected where possible to be dominated by a single landscape class expected

18 to strongly influence water quality as defined and identified from maps and a field visit.

19 Simple random sampling of first order streams would include numerous very mixed 12

C:\Users\dgal|Desktop\N505340.docx 
1 subcatchments with little information for the estimation of parameters associated with

2 landscape differences in drainage water quality. The purpose here is to demonstrate a

3 modelling approach at an example catchment, rather than to attempt to provide a fully

4 parametrised model which can be applied without modification throughout the United

5 Kingdom. The modelling approach may be applied elsewhere, with estimation of local

6 parameters. If used elsewhere with the parameter values estimated for the Conwy,

7 residual analysis would provide some insight into differences between the study

8 catchment and the Conwy. eThe three landscape classifications used in modelling were

9 based on:

1. Soil class

2. Land cover

3. Dual soil/land cover ("landscape", cf Evans et al. ${ }^{14}$ )

\section{Soil class}

15 We use the England and Wales National Soil Resources Institute (NSRI) LandIS soil

16 classification http://www.landis.org.uk/index.cfm, combining some soil classes which

17 are either poorly represented or distributed in the catchment. The final classes used are

18 shown in Table 1.

19

\section{Table 1. Soil classification}




\begin{tabular}{|l|l|}
\hline Soil class & $\begin{array}{l}\text { LandIS soil } \\
\text { association }\end{array}$ \\
\hline Humic ranker & 311 \\
\hline Brown soil & 541,561 \\
\hline $\begin{array}{l}\text { Brown podzolic } \\
\text { soil }\end{array}$ & 611,612 \\
\hline Stagnopodzol & 654 \\
\hline Stagnogley & 713 \\
\hline $\begin{array}{l}\text { Stagnohumic } \\
\text { Gley }\end{array}$ & 721 \\
\hline Peat & 1013 \\
\hline
\end{tabular}

1

2

3 Land cover (LCM)

4 The UK 2007 Land Cover Map (LCM2007,

5 http://www.ceh.ac.uk/LandCoverMap2007.html) includes 23 classes at UK scale. After

6 some consolidation of major land cover groups in to account for poor representation in

7 the Conwy catchment, we use the classes shown in Table 2.

8

9

Table 2. Land cover class

\begin{tabular}{|l|l|}
\hline \multicolumn{1}{|c|}{ Land cover class } & \multicolumn{1}{|c|}{$\begin{array}{c}\text { LCM } 2007 \\
\text { class }\end{array}$} \\
\hline Broadleaved Woodland & 1 \\
\hline Coniferous Woodland & 2 \\
\hline Arable and Horticulture & 3 \\
\hline Improved Grassland & 4 \\
\hline Unimproved Grassland & 5,6 \\
\hline
\end{tabular}

14

C:\Users\dgal\Desktop\N505340.docx 


\begin{tabular}{|l|l|}
\hline Acid Grassland & 8 \\
\hline Heather & 10 \\
\hline Heather Grassland & 11 \\
\hline Bog & 12 \\
\hline Montane and Rock & 13,14 \\
\hline Fresh water & 16 \\
\hline Built up & 22,23 \\
\hline
\end{tabular}

1

\section{Dual soil/land cover ("Iandscape")}

3 In a previous study of the Conwy catchment, Evans et al ${ }^{14}$ identified five major

4 landscape classes, defined by combining soil and land cover classes. They started from a

5 landscape division based on all soil and land cover combinations present and clustered

6 these into five classes based on available stream water quality data The grouped

7 landscapes are defined as "Mountain", "Peat", plantation coniferous forestry ("Forest"),

8 gley moorland ("Gley") and enclosed farmland ("Farm"), and used these to model water

9 quality in the catchment. The combination of class groups used in the landscape

10 definition is shown in Table 3.

\begin{tabular}{|l|l|l|}
\hline $\begin{array}{l}\text { LandIS soil } \\
\text { association }\end{array}$ & $\begin{array}{l}\text { LCM2007 } \\
\text { land cover } \\
\text { class }\end{array}$ & $\begin{array}{l}\text { Combined } \\
\text { landscape } \\
\text { class }\end{array}$ \\
\hline & 1,2 & "Forest" \\
\hline & $3,4,5,23$ & "Farm" \\
\hline 1013 & & "Peat" \\
\hline 721 & & "Gley" \\
\hline
\end{tabular}

15

C:\Users\dgal\Desktop\N505340.docx 


\begin{tabular}{|lr|l|l|}
\hline $\begin{array}{l}\text { All present } \\
\text { except } 721 \text { and } \\
1013\end{array}$ & $8,10,11,13,14$ & "Mountain" \\
\hline
\end{tabular}

2 This choice of grouping is also supported by evidence from other studies of enhanced

3 atmospheric deposition of some water quality variables, differences in soil processes in

4 different soil types, particularly between peat and mineral soils, and the strong

5 association between water quality and farming, where the fertility of the soil is

6 artificially influenced by farming practices ${ }^{12,21,11}$.

8 The three classifications do not explicitly include a number of covariates which are likely

9 to influence water quality, including topography, slope and precipitation. However,

10 these covariates are highly correlated with catchment characteristics and their influence

11 is therefore partly accounted for within the classification schemes.

\section{$12 \quad 3.2$ Sample collection and chemical analysis}

13 Field samples of stream water were collected in polypropylene bottles and stored at $4^{0} \mathrm{C}$

14 prior to analysis. Major ions sodium, potassium, calcium, magnesium were analysed

15 using ICP-OES; chloride and sulphate using ion chromatography; nitrate colorimetrically

16 using a SEAL AQ2 discrete analyzer; $\mathrm{pH}$ by $\mathrm{pH}$ electrode and non-purgeable organic

17 carbon (NPOC), taken to be equivalent to dissolved organic carbon (DOC), using a Skalar 16

C:\Users\dgal\Desktop\N505340.docx 
1 Formacs analyser. The data and details of the chemical analysis methods used may be

2 accessed at Cooper et al. ${ }^{22}$.

\section{$3 \quad 3.3$ Model implementation}

4 We used the nlmer routine in the $\mathrm{R}$ package (http://www.r-project.org/) lme4 for

5 non-linear model fitting. We fitted seven models of increasing complexity. We used the

6 model shown by equation (5) as the most complex, with sub-models as shown in Table

76.

Table 6. Model components (cf. Equation (5))

\begin{tabular}{|c|c|c|c|}
\hline $\begin{array}{l}\text { Model } \\
\text { no. }\end{array}$ & Model & Spatial effect $C_{s}$ & $\begin{array}{l}\text { Temporal effect } \\
\lambda_{t}\end{array}$ \\
\hline 1 & Simple mean & - & - \\
\hline 2 & Random spatial only & $\varsigma_{s}$ & - \\
\hline 3 & Random temporal only & - & $\xi_{t}$ \\
\hline 4 & Random spatial and temporal & $\varsigma_{s}$ & $\xi_{t}$ \\
\hline 5 & $\begin{array}{l}\text { Random and fixed spatial; } \\
\text { random temporal }\end{array}$ & $\log \left(\sum_{j} p \vartheta_{s, j}\right) \xi_{s}$ & $\xi_{t}$ \\
\hline 6 & $\begin{array}{l}\text { Random and fixed temporal; } \\
\text { random spatial }\end{array}$ & $\varsigma_{s}$ & $\left.\log \left(f_{t} \phi l_{k}\right)\right) \xi_{t}$ \\
\hline 7 & $\begin{array}{l}\text { Random and fixed temporal and } \\
\text { spatial }\end{array}$ & $\log \left(\sum_{j} p \vartheta_{, j}{ }_{j}\right) \xi_{s}$ & $\left.\log \left(f \notin c_{k}\right)\right) \xi_{t}$ \\
\hline
\end{tabular}

9

17

C:\Users\dgal\Desktop\N505340.docx 


\section{Results}

\section{$2 \quad$ 4.1 Differences between models and choice of spatial covariates}

3 Model performance is first assessed using AIC (Akaike Information Criterion) values. The

4 lowest AICs for the 3 spatial classifications were given by model 7 for most water quality

5 variables, with the combined landscape classification in most cases giving the lowest

6 AIC. Exceptions were potassium, for which model 5 was preferred. For both nitrate and

7 potassium, the land cover classification gave lower AIC than the combined landscape.

8 This is thought due to greater resolution of agricultural land using LCM2007 land cover,

9 where the leaching of these two nutrients varies considerably within different crop and

10 grazing regimes. The apparent superiority of Model 5 for potassium is due to the lack of

11 a consistent seasonal pattern in measured concentrations. With the exception of DOC

12 and nitrate, the poorest model fit in terms of AIC was for the soil classification. For the

13 major cations $\mathrm{Na}, \mathrm{K}, \mathrm{Mg}$, Ca fitting a random temporal effect (Model 3) gives an

14 estimated variance of the random effect of zero, indicating that there is no detected

15 seasonal variability between sites. With the exception of $K$, a seasonal effect is

16 detectable for these variables when explicitly parametrised (Models 6 and 7). DOC, NO3

17 and $\mathrm{pH}$ show both seasonal effects and differences between classes within classification

18 schemes. Results are summarised graphically in Figure 2 for models 4 to 7 . Note that 18

C: $\mid$ Users\dgal|Desktop\N505340.docx 
1 models 4 and 6 include no spatial component, so their AIC is the same for all choices of

2 spatial classification.
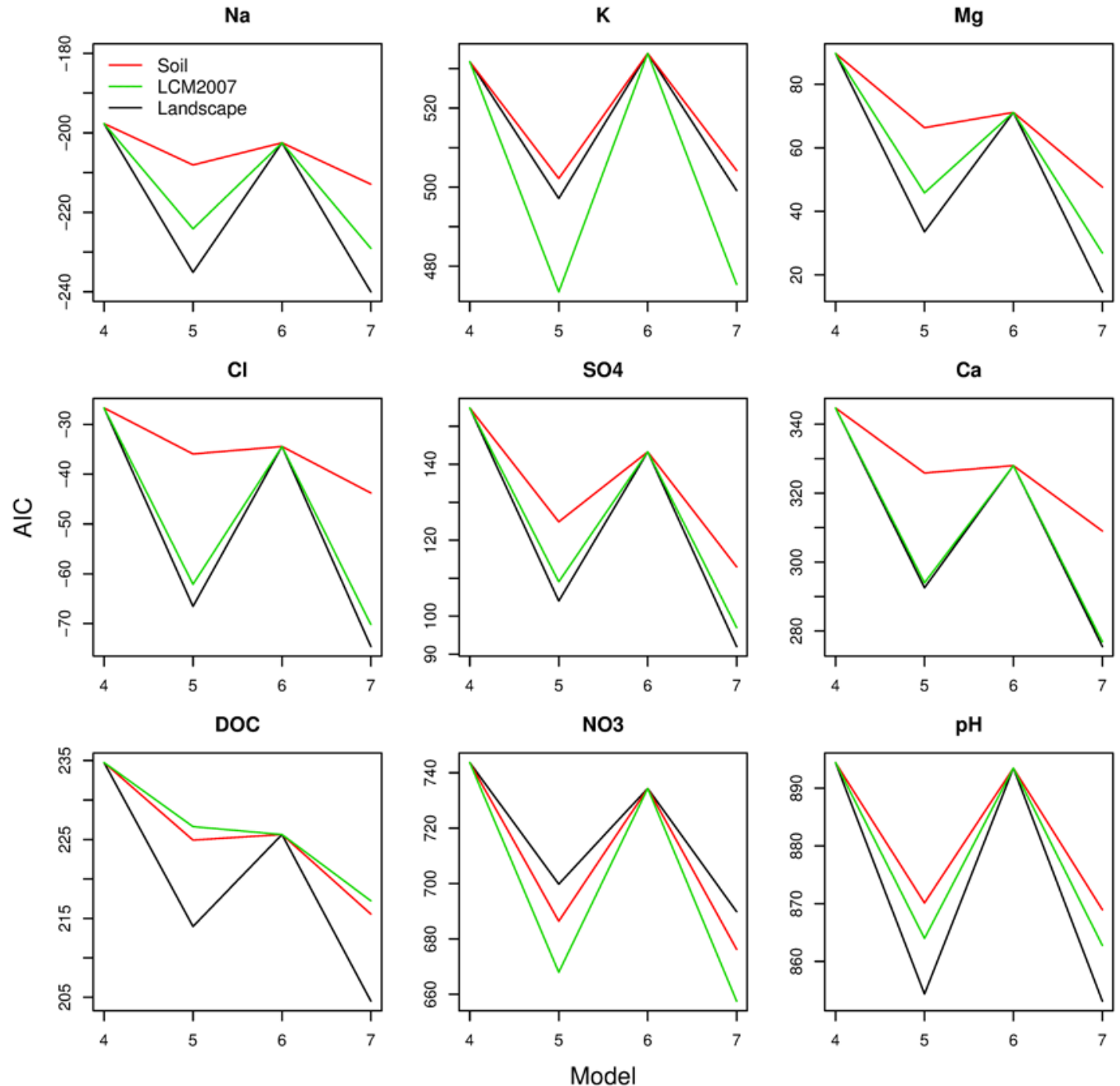

3

4 Figure 2. AIC values by determinand and model

5 Model 4 includes spatial and temporal effects as random only. For models 5 to 7 , some

6 of this variability is accounted for by fixed effects and some by random effects, but the 19

C:\Users\dgal\Desktop\N505340.docx 
1 total spatial and temporal variability accounted for remains the same as for model 4.

2 The variance proportions associated with the application of model 4 to each water

3 quality variable are shown in Figure 3. The dominant source of variability is spatial

4 rather than temporal for all variables. The seasonal effect is greatest for DOC, nitrate 5 and $\mathrm{pH}$.

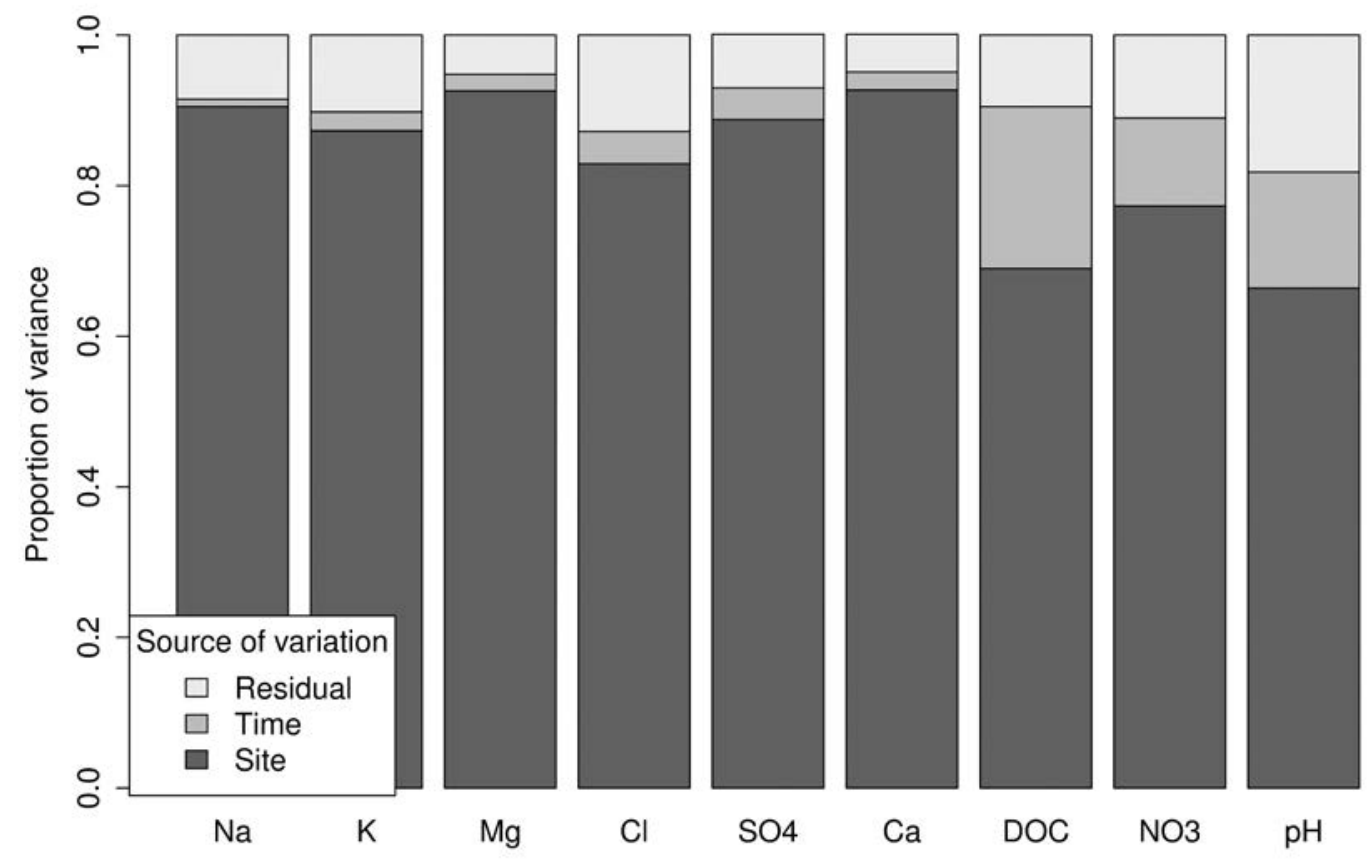

6

$7 \quad$ Figure 3. Proportions of variance accounted for by site, sampling time and 8 residual for Model 4 


\section{$1 \quad 4.2$ Differences between choice of spatial and temporal covariates}

2 Figures 4 and 5 show the spatial and temporal variability accounted for by the fixed

3 effects model, as a proportion of the variability accounted for by a random effect alone.

4 The figures suggest that the quality of fit between variables is quite consistent within

5 landscape classifications. Both the land cover and the landscape classification give

6 similarly high explanatory power. However, the landscape classification has fewer

7 parameters and therefore tends to have lower AIC values. Figure 5 shows the very high

8 proportion of the temporal variability which is accounted for by the seasonal model. The

9 data for these variables suggest that spatial class influences concentrations, but that

10 there is consistency between sampling times at individual sampling points. That is to

11 say, site effects within spatial classes are significant and persistent. Differences between

12 sampling occasions tend to be consistent regardless of site or spatial class. 


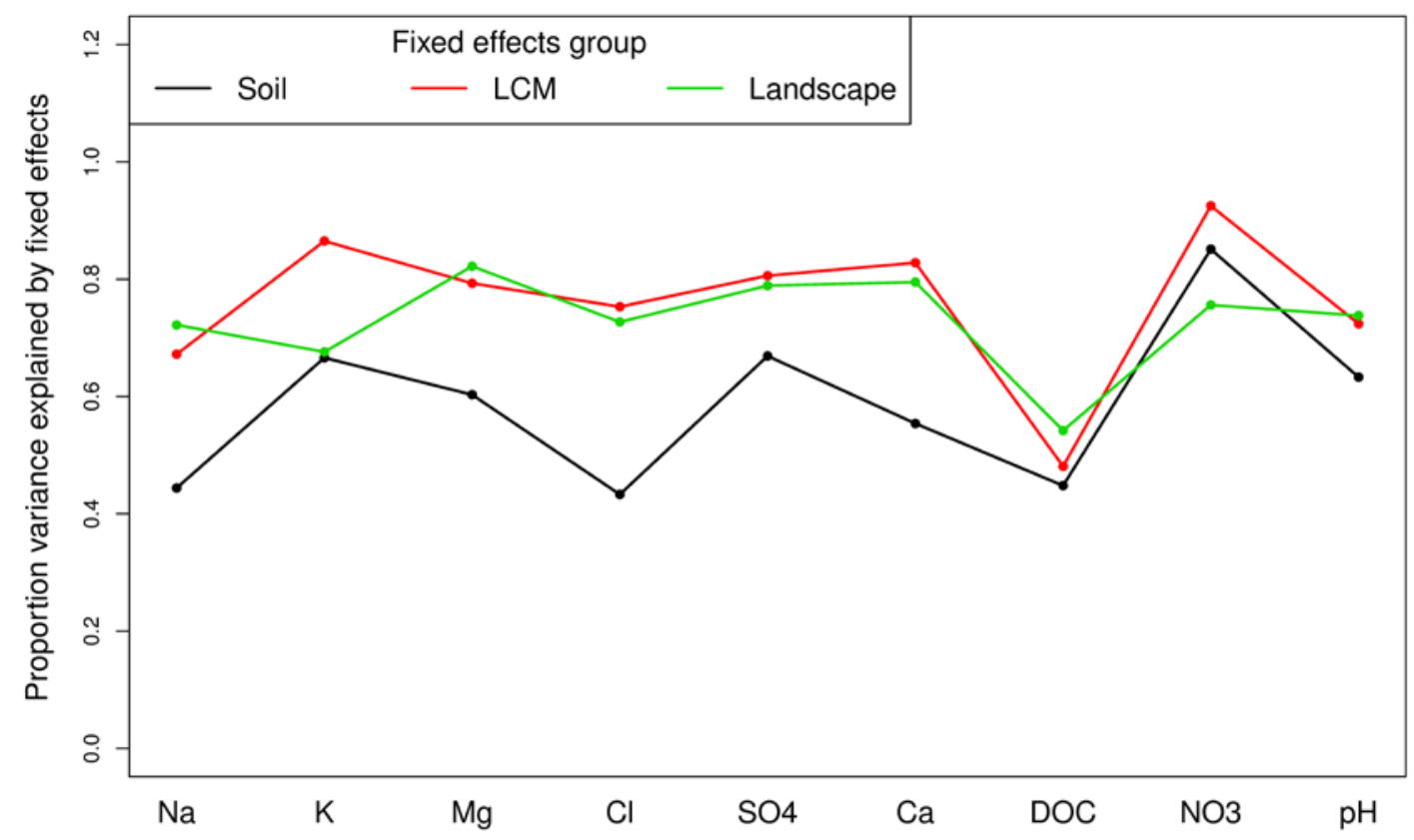

1

2 Figure 4. Performance of fixed effects groups in terms of site variance 


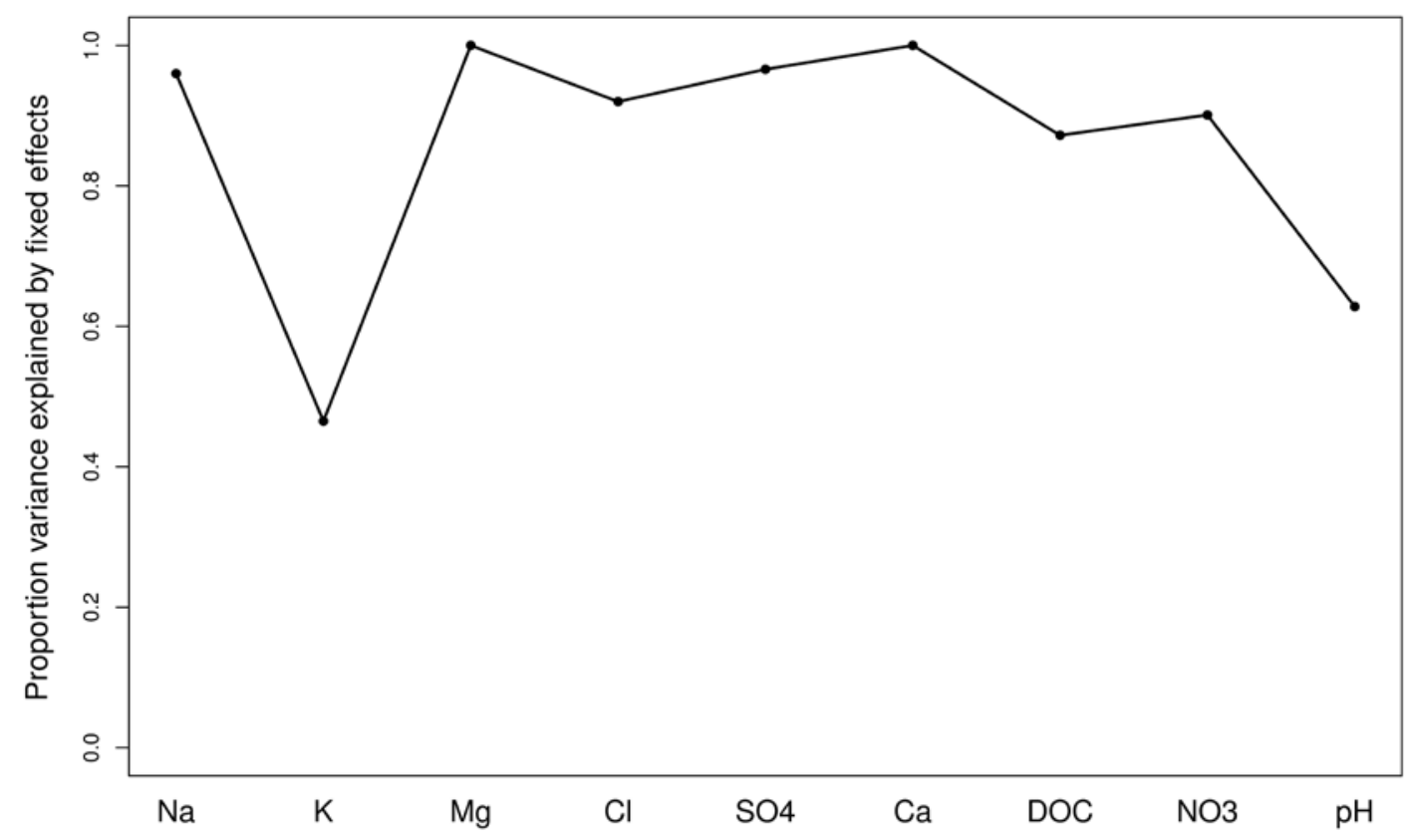

1

2 Figure 5. Performance of seasonal fixed effect in terms of time variance accounted for

\section{$4 \quad 4.3$ Residual analysis}

5 Our analysis has been applied to individual water quality variables without accounting

6 for any correlation structure between them. Even if the model gives an excellent fit for

7 individual variables, the residual sequences for variables which are strongly related may

8 still show strong correlation. First ignoring between-site correlation we consider the 
1 residual between-variable relationships. Returning to the logged raw data, the first two

2 scaled principal components are plotted in Figure 6.

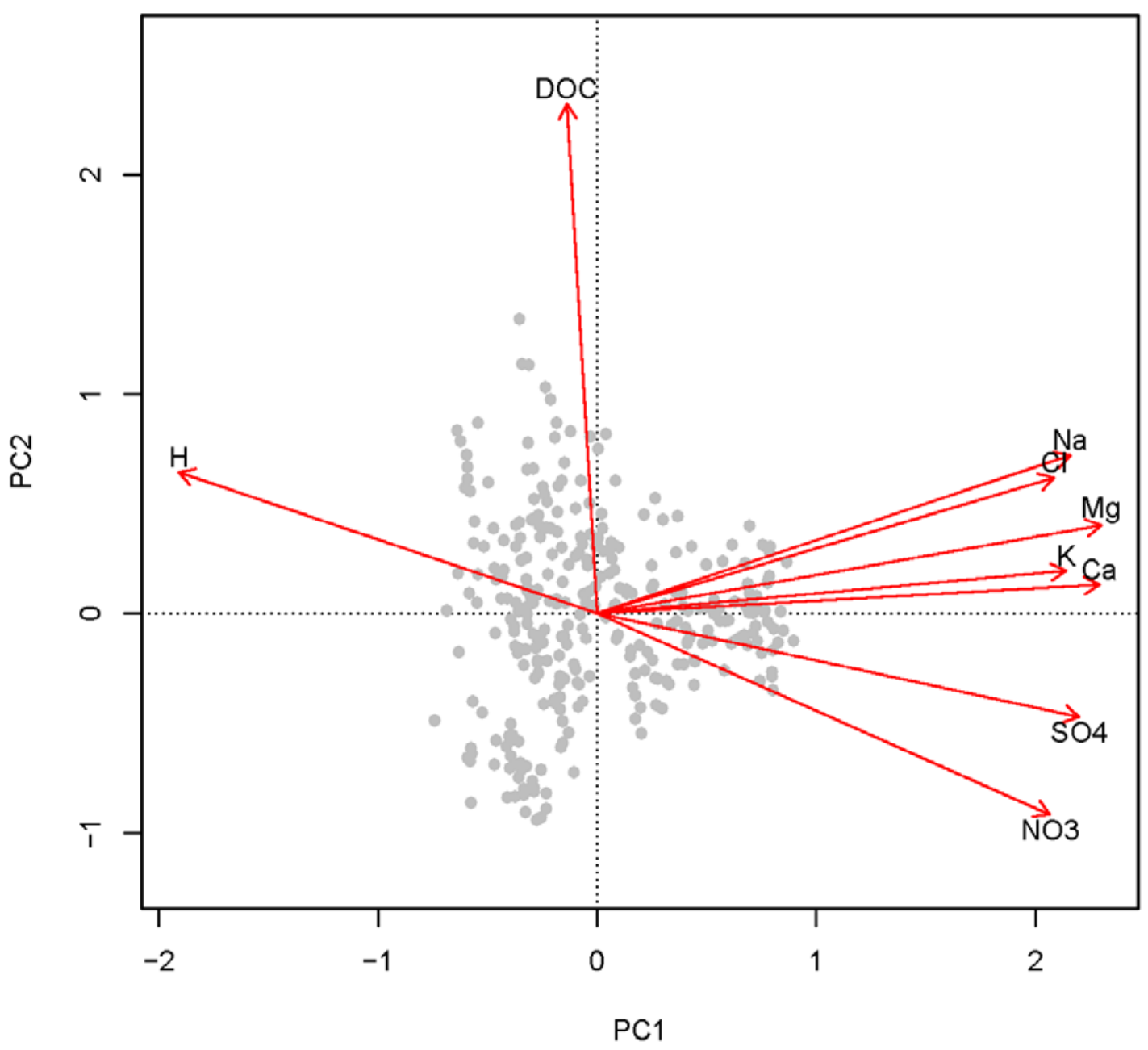

3

Figure 6. Scaled principal components plot for $\log ($ raw data) 
1 Figure 6 is strongly influenced by the agricultural component of water quality, which

2 tends to show high concentrations of all major ions apart from hydrogen and dissolved

3 organic carbon. Sulphate and nitrate are included amongst these major ions, and appear

4 to be inversely related to hydrogen ion concentration, despite being acid anions. These

5 two major anions are associated with the major cations rather than hydrogen in

6 satisfying a change balance in stream water. 


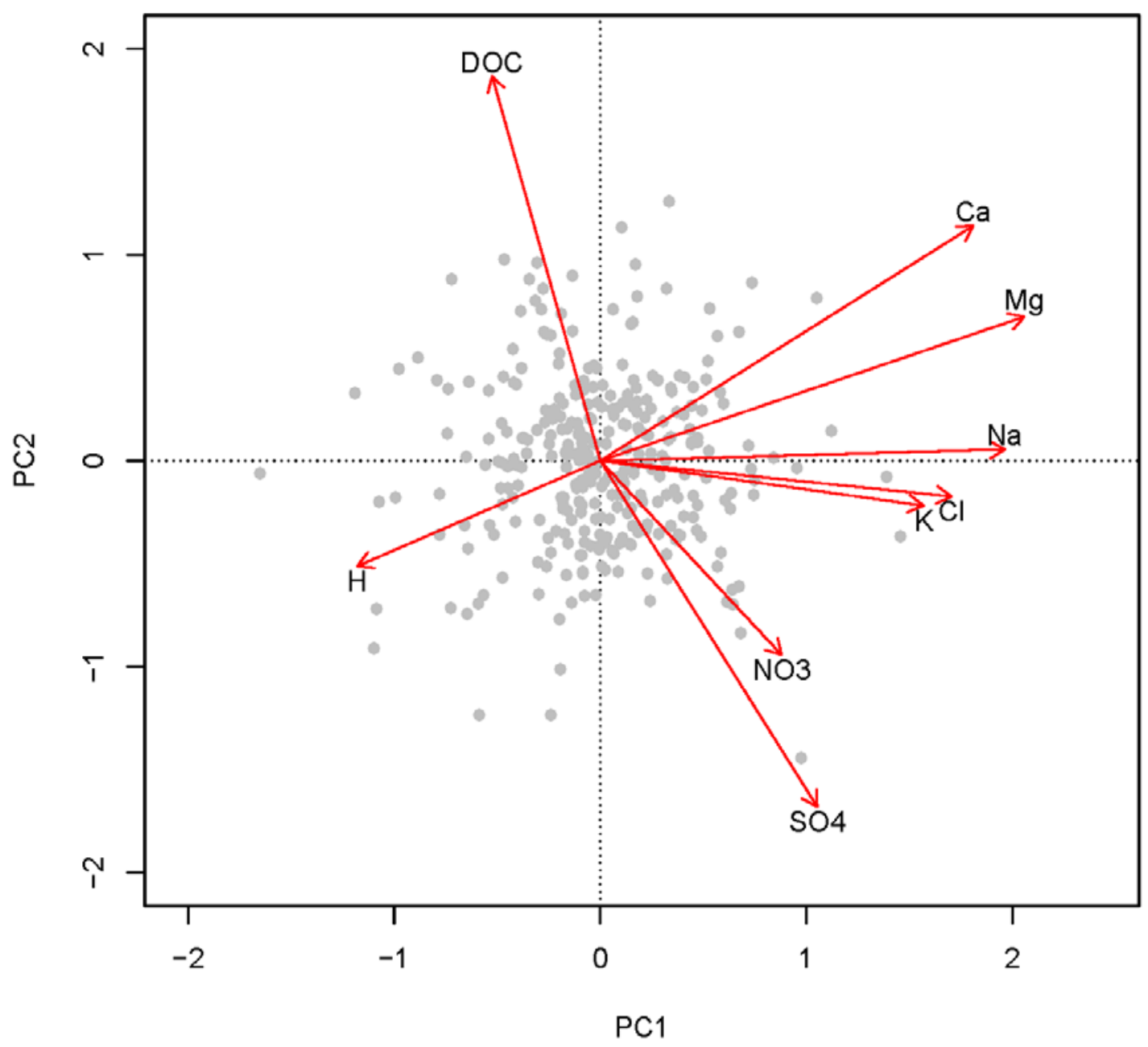

1

3 Figure 7 shows scaled principal components of the residual series. One of the main

4 effects of model fitting is to reduce the strong influence of agriculture. The remaining

5 variability shows the strongest inverse relationships between DOC and sulphate/nitrate 26

C:\Users\dgal\Desktop\N505340.docx 
1 and between hydrogen and calcium/magnesium. Plots of DOC against sulphate residuals

2 for individual sites suggest that the relationship is strongest for those sites with high

3 concentrations of peat. The inverse relationship between DOC and sulphate in upland

4 waters has been noted and explained elsewhere ${ }^{23}$. Our results show that the inverse

5 relationship holds at catchment scale. The inverse relationship with nitrate is believed to

6 be related to an unaccounted site by time interaction associated with seasonal

7 differences between these two variables. In peat subcatchments, high DOC is measured

8 during summer when nitrate concentrations are low due to plant uptake.

10 To examine clustering of residual behaviour by site, we first take principal components

11 of the (39 site $\times 8$ field excursion) row $\times$ (9 determinand) column matrix of residuals.

12 Each principal component then represents an independent linear combination of

13 determinands having diminishing influence on the overall variance of the residuals. We

14 then reconfigure the principal components matrix to give a $72 \times 39$ matrix, each column

15 of which comprises 8 values over time $\times 9$ principal components. We can then cluster

16 the sites using these data to investigate relationships between sites, associated with

17 interaction terms related to site and time. We use the hclust routine of $\mathrm{R}$ to generate 18 clusters.

19

27

C: $\mid$ Users $\backslash$ dgal|Desktop\N505340.docx 
1 Cluster analysis of the transformed residuals generates 7 natural clusters of sites. The

2 interpretation of these clusters is that the chemistry of cluster members has similar site

3 by time interactions unaccounted for by the model. A comparison of the locations of

4 cluster members with the original dominant landscape classes suggests some 5 correspondence (Table 7).

6

7 Table 7. Relationship between residual clusters and landscape 8 classes - allocation by site

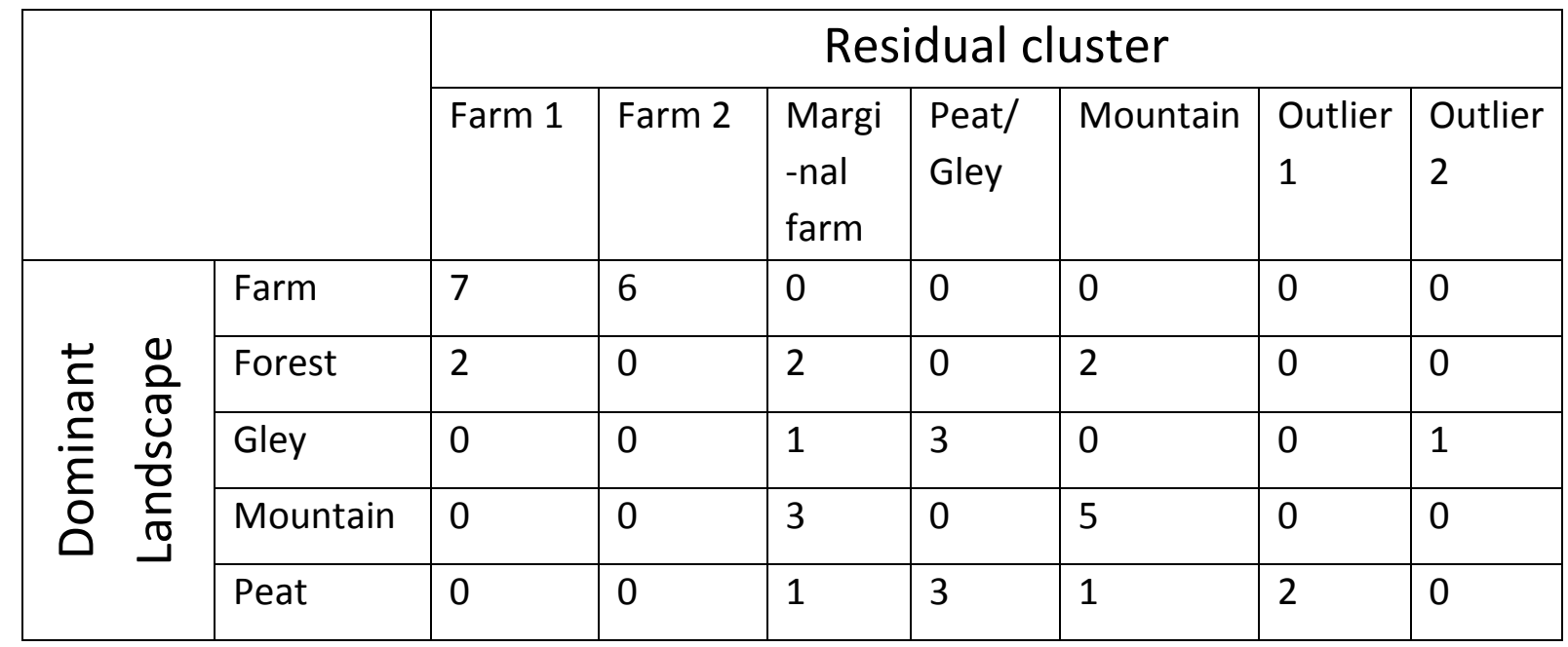

9

10 Two clusters of residuals correspond approximately to the single original "farm"

11 landscape classification. A comparison of the raw data suggests that this split is based

12 on higher $\mathrm{Na}, \mathrm{Mg}$ and $\mathrm{SO} 4$, and lower $\mathrm{DOC}$ in one group. Of the remaining clusters, it is

13 not possible to identify one associated with forest, though mountain and peat clusters 28

C:\Users\dgal\Desktop\N505340.docx 
1 are identifiable, and an additional cluster associated with subcatchments at the upper

2 extreme of enclosed agriculture (marginal farm). Three outlier sites are identified, two

3 of which are adjacent subcatchments. Within clusters, there is some evidence that

4 nearby sites (on a $1 \mathrm{~km}$ scale) have more similar chemistry than more distant sites within

5 the same cluster. Table 7 indicates that the simple spatio-temporal model fails to

6 capture some interactions between season and landscape class, particularly associated

7 with agricultural land use. This suggests that there would be benefit in modelling these

8 landscapes separately.

\section{Discussion}

11 The analysis confirms that most of the variability in water quality can be described by

12 the spatial component of the model. This is no doubt partly because of the wide range

13 of landscapes present in the catchment, and the absence of hydrological extremes from

14 the limited sequence of measurements made. Clearly longer time series of data would

15 provide greater opportunities for identifying temporal relationships between water

16 quality variables and covariates. For base cations there is either little seasonal

17 variability, or it is not consistent across landscapes. The greater seasonal variability in

$18 \mathrm{pH}$, nitrate and DOC is interpretable in terms of known biogeochemical processes. DOC

19 concentrations are higher in summer when there is greater microbial activity, while 29

\section{C: $\mid$ Users $\backslash$ dgal|Desktop\N505340.docx}


1 nitrate is higher in winter when there is less uptake. The $\mathrm{pH}$ is higher is summer when

2 flow is lower and weathering effects on stream water quality are greater.

3 The principal components analysis of residuals between variables shows how the

4 remaining interactions between variables splits into an inverse relationship between

5 DOC and sulphate and nitrate, and an inverse relationship between hydrogen ion

6 concentration and calcium and magnesium, with sodium, potassium and chloride

7 grouped together. These relationships are interpretable as due to differential

8 weathering in deeper soils, and an interchange between sulphate and DOC particularly

9 in peaty soils.

10 Cluster analysis of residuals by site suggests that many of the original landscape

11 classification units are still distinguishable. This is consistent with there being important

12 landscape by time interactions which are unaccounted for by the model. The lack of an

13 apparent forest cluster suggests the model has successfully accounted for any

14 distinguishing characteristics of this landscape. The subcatchments formerly classified as

15 forest are now grouped according to the pre-forest landscape. The cluster analysis also

16 suggests peat and gley residuals are not distinguishable. There are close field similarities

17 between these two landscapes; both are upland and poorly drained, with the gley

18 generally having less development of peat. Both are nutrient poor with high DOC

19 concentrations. The suggested new cluster of marginal farmland corresponds to a 30

C:\Users\dgal\Desktop\N505340.docx 
1 recognised landscape in upland Wales named ffridd. This is a region characterised by

2 bracken, coarser grasses and scattered bushes between the enclosed fields and the

3 open hill. The two separate clusters for farmland suggest a need for a further split based

4 on DOC concentrations. Of the three outliers, two show unusually high sodium and

5 chloride concentrations. The sodium to chloride ratio is consistent with a sodium

6 chloride source in the subcatchment. A marine source would be indicated by raised

7 concentrations of magnesium, which are not observed. Since both subcatchments

8 receive drainage from a road which is salted in winter, we assume that road salt is the

9 source of the elevated sodium and chloride concentrations. The third outlier is believed

10 to be both misclassified and to include an unidentified point source. While the mapped

11 soil classification is gley, field evidence suggests the soil is largely peat. Elevated

12 concentrations of $\mathrm{Ca}$ and $\mathrm{Mg}$ at this site at low flows suggest the existence of a point or

13 geological source of base-rich weathering.

14

15 Water quality monitoring programmes generate large volumes of multivariate spatio-

16 temporal data. While these can be used to calibrate models, a relatively simple

17 statistical analysis of the data can aid in the interpretation of such data by identifying

18 common features between sites, between sampling occasions and between variables.

19 The framework used here is an example of how such a model can be used to identify 31

C: $\mid$ Users $\backslash$ dgal|Desktop\N505340.docx 
1 proportions of variability attributable to various sources; identify outlier sampling sites;

2 identify likely additional diffuse or point sources and identify features common to

3 particular landscapes.

4

\section{Acknowledgements}

6 This work was funded by the UK Natural Environment Research Council, through the

7 Centre for Ecology and Hydrology. We acknowledge contributions by Annette Burden

8 and others at $\mathrm{CEH}$ Bangor to field sampling and to Alan Lawlor, formerly of CEH

9 Lancaster, and others at CEH Lancaster who carried out the chemical analysis of

10 samples. 


\section{References}

1 P. J. Johnes. Evaluation and management of the impact of land use change on the nitrogen and phosphorus load delivered to surface waters: the export coefficient modelling approach. J. Hydrol., 1996, 183, 323-349.

2 F. Worrall and T. P. Burt. The impact of land use change on water quality at the catchment scale: the use of export coefficient and structural models. J. Hydrol., 1999, 221, 75-90.

$3 \mathrm{~J}$. Zobrist and P. Reichert. Bayesian estimation of export coefficients from diffuse and point sources in Swiss watersheds. J. Hydrol., 2006, 329, 207- 223

4 R. A. Young, C. A. Onstad, D. D. Bosch, and W. P. Anderson. AGNPS: a non-point source pollution model forevaluating agricultural watersheds. J. Soil Water Conserv., 1989, 44, 168-173.

5 J. G. Arnold, J. R. Williams, R. Srinivasan and K. W. King. SWAT: Soil and water assessment tool Model documentation. USDA, ARS, Grassland Soil and Water Research Laboratory, Temple, TX. 1996. 
6 A. S. Donigian Jr., J. C. Imhoff, B. Bicknell and J. L. KittleJr. Application guide for Hydrological Simulation Program--Fortran (HSPF): U.S. Environmental Protection Agency, Environmental Research Laboratory, Athens, Ga., EPA-600/3-84-065, 1984, 177 p.

7 E. I. Lord and S. G. Anthony. MAGPIE: A modelling framework for evaluating nitrate losses at national and catchment scales. Soil UseManage., 2000, 16, Issue Supplement s1, 167-174.

8 D. K. Borah and M. Bera. Watershed-scale hydrologic and non-point-source pollution models: Review of mathematical bases. Trans. ASAE, 2003, 46(6), 1553-1566.

9 D. K. Borah and M. Bera. Watershed-scale hydrologic and non-point-source pollution models: Review of applications. Trans. ASAE, 2004, 47(3), 789-803.

10 M. S. Cresser, R. Smart, M. F. Billett, C. Soulsby, C. Neal, A. Wade, S. Langan and A. C. Edwards. Modelling water chemistry for a major Scottish river from catchment attributes. J. Appl. Ecol., 2000, 37, (Suppl. 1),171-184.

11 R. C. Helliwell, M. C. Coull, J. J. L. Davies, C. D. Evans, D. Norris, R. C. Ferrier, A. Jenkins and B. Reynolds. The role of catchment characteristics in determining surface water nitrogen in four upland regions in the UK. Hydrol. Earth Syst. Sc., 2007, 11(1), 356-371. 
12 P. J. Dillon and L. A. Molot. Effect of landscape form on export of dissolved organic carbon, iron, and phosphorus from forested stream catchments. Water Resour. Res., 1997, 33(11): 2591-2600.

13 D. M. Cooper, R. C. Helliwell, M. C. Coull. Predicting acid neutralising capacity from landscape classification: application to Galloway, south-west Scotland. Hydrol. Process.,2004, 18, 455-471.

14 C. D. Evans, D. M. Cooper, S. Juggins, A. Jenkins and D. Norris. A linked spatial and temporal model of the chemical and biological status of a large, acid-sensitive river network. Sci. Total Environ., 2006, 365, 167-185.

15 D. M. Robertson, D. A. Saad and D. M. Heisey. A regional classification scheme for estimating reference water quality in streams using land-use-adjusted spatial regression tree analysis. Environ. Manage., 2006, 37(2), 209-229.

16 S. Shrestha, F. Kazama, L. T. H. Newham, M. S. Babel, R. S. Clemente, H. Ishidaira, K. Nishida and Y. Sakamoto. Catchment scale modelling of point source and non-point source pollution loads using pollutant export coefficients determined from long-term instream monitoring data. Journal of hydro-environment research, 2008, 2(3), 134-147.

35

C: $\mid$ Users $\backslash$ dgal|Desktop $\backslash$ N505340.docx 
17 S. Shrestha, F. Kazama and L. T. H. Newham. A framework for estimating pollutant export coefficients from long-term in-stream water quality monitoring data Environ. Modell. Softw., 2008, 23(2), 182-194.

18 R. A. Smith, G. E. Schwartz and R. B. Alexander. Regional interpretation of water quality data. Water Resour. Res., 1997, 33, 2781-2798.

19 R. B. Alexander, A.H.Smithand G. E. Schwartz. Estimates of diffuse phosphorus sources in surface waters of the United States using a spatially referenced watershed model. Water Sci, Technol., 2004 49(3), 1:10

20 C. Wellen, G. B. Arhonditsis, T. Labencki and D. Boyd. A Bayesian methodological framework for accommodating interannual variability of nutrient loading with the SPARROW model. Water Resour. Res., 2012, 48, W10505, doi: 10.1029/2012WR011821.

21 P. Srivastava, K. W. Migliaccio and J. Simunek. Landscape Models for Simulating Water Quality at Point, Field, and Watershed Scales. Transactions of the ASABE, 2007 50(5), 1683-1693

22 D. M. Cooper, C. D. Evans, D. A. Norris, A. Burden and A. Lawlor. Conwy Catchment Spatial Water Chemistry Dataset. NERC-Environmental Information Data Centre doi:10.5285/c53a1f93-f64c-4d84-82a7-44038a394c59. 2013.

36

C:\Users\dgal\Desktop\N505340.docx 
23 S. M. Daniels, M. G. Evans, C. T. Agnew, T. E. H. Allott. Sulphur leaching from headwater catchments in an eroded peatland, South Pennines, UK. Sci. Total Environ.,2008, 407, 481-496. 